\title{
ПОЖАРНЫЙ НАДЗОР ЗА СОДЕРЖАНИЕМ ОБЩЕГО ИМУЩЕСТВА МНОГОКВАРТИРНОГО ДОМА
}

\begin{abstract}
Аннотация: Статья посвящена изучению проблем пожарного надзора за содержанием общего имущества многоквартирного дома. Рассматриваются требования пожарной безопасности к содержанию и ремонту общего имущества собственников помещений в многоквартирном доме. Автором предлагаются правовые меры по разрешению юридических проблем в сфере осуществления пожарного надзора обслужсивания и эксплуатации жилищного фонда. Ключевые слова: Юриспруденция, пожарный надзор, содержание общего имущества, многоквартирный дом, организациии по обслуживанию жилищного фонда, жилищно-эксплуатирующие организации, жилищный фонд, требования пожарной безопасности, противопожарная защчита, противопожарные требования
\end{abstract}

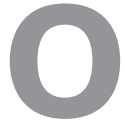

беспечение необходимого уровня пожарной безопасности и минимизация потерь вследствие пожаров является важным фактором устойчивого социально-экономического развития Российской Федерации.

В настоящее время более 70 процентов пожаров происходит в жилом секторе. Огнем уничтожается около 1,2 млн. кв. метров жилья. Размеры уничтоженной огнем жилой площади составляют более 3 процентов объемов вводимого жилья. На долю пожаров в зданиях жилого сектора приходится $88-$ 90 процентов всех погибших и около 70 процентов травмированных на пожарах людей. Уровень риска пожаров в Российской Федерации выше, чем в других экономически развитых странах. ${ }^{1}$

Поэтому требования пожарной безопасности обязательны для исполнения всеми собственниками помещений в многоквартирном доме, организациями, в управлении которых находятся многоквартирные дома, в том числе товариществами собственников жилья, а также управляющими организациями (компаниями), ремонтно-эксплуатационными и специализированными предприятиями различных организационно-правовых форм и форм собственности, выполняющими работы по содержанию и ремонту жилищного фонда.

Под требованиями пожарной безопасности понимаются специальные условия социального и (или) технического характера, установленные федеральным законодательством, в том числе Федеральным законом от 21.12.1994 г. № 69-Ф3 «О пожарной безопасности», ${ }^{2}$ (далее по тексту - Закон о пожар-

\footnotetext{
${ }^{1}$ Федеральная целевая программа «Пожарная безопасность в Российской Федерации на период до 2012 года», утвержденная Постановлением Правительства Российской Федерации от 29 декабря 2007 г. № 972 // Собрание законодательства РФ. - 2008. - № 3. - Ст. 180.

${ }^{2}$ Федеральный закон от 21.12.1994 г. № 69-Ф3 (ред. от 29.12.2010) «О пожарной безопасности» // Собрание законодательства РФ. 1994. - № 35. - Ст. 3649.
}

ной безопасности), Федеральным законом от 22.07.2008 г. № 123-Ф3 «Технический регламент о требованиях пожарной безопасности», ${ }^{3}$ (далее по тексту - Технический регламент о требованиях пожарной безопасности), законами или иными нормативными правовыми актами субъектов Российской Федерации и органов местного самоуправления, а также нормативными документами уполномоченных государственных органов противопожарной службы в целях обеспечения противопожарной безопасности при проведении работ по содержанию и ремонту жилищного фонда. Согласно пункту 1 Положения о государственном пожарном надзоре,${ }^{4}$ утвержденного Постановлением Правительства Российской Федерации от 21 декабря 2004 г. № 820, федеральным органом исполнительной власти, уполномоченным осуществлять государственный пожарный надзор в Российской Федерации, в том числе за содержанием и ремонтом общего имущества многоквартирных домов является Министерство Российской Федерации по делам гражданской обороны, чрезвычайным ситуациям и ликвидации последствий стихийных бедствий (далее по тексту - МЧС РФ) и его территориальные органы в субъектах Российской Федерации.

В целях контроля за соблюдением требований пожарной безопасности в процессе содержания общего имущества собственников помещений в многоквартирном доме и пресечения их нарушений органы МЧС РФ вправе проводить обследования и проверки, а также давать обязательные для исполнения предписания по устранению нарушений требований пожарной безопасности.

\footnotetext{
3 Федеральный закон от 22.07.2008 г. № 123-Ф3 «Технический регламент о требованиях пожарной безопасности» // Собрание законодательства РФ. - 2008. - № 30 (ч. 1). - Ст. 3579

${ }^{4}$ Положение о государственном пожарном надзоре, утвержденное Постановлением Правительства Российской Федерации от 21 декабря 2004 г. № 820 // Собрание законодательства РФ. 2004. - № 52 (ч. 2). - СТ. 5491.
} 
Проанализировав положения законодательства Российской Федерации о пожарной безопасности, по мнению автора, требования пожарной безопасности при проведении работ по содержанию и ремонту жилищного фонда можно классифицировать следующим образом:

- требования пожарной безопасности к содержанию систем вентиляции, кондиционирования и противодымной защиты;

- требования пожарной безопасности к содержанию придомовых территорий и мест общего пользования;

- требования пожарной безопасности к содержанию и ремонту систем отопления;

- требования пожарной безопасности к содержанию сетей противопожарного водоснабжения, установок пожарной сигнализации и пожаротушения;

- требования пожарной безопасности к содержанию и ремонту электрооборудования.

Систематизированные автором требования пожарной безопасности к содержанию и ремонту общего имущества многоквартирного дома в обязательном порядке, по нашему мнению, должны находить свое закрепление в инструкциях о мерах пожарной безопасности.

Подобные инструкции о мерах пожарной безопасности разрабатываются должностными лицами жилищно-эксплуатирующих организаций, ответственными за обеспечение пожарной безопасности при проведении работ по содержанию и ремонту жилищного фонда, на основе нормативнотехнических (нормативных) и других документов, содержащих требования пожарной безопасности, для каждого вида или для комплекса технологически взаимосвязанных видов работ по содержанию и ремонту жилищного фонда исходя из специфики пожарной опасности зданий, инженерных систем и оборудования, технологических процессов по ремонту и содержанию жилищного фонда.

В частности, в инструкции о мерах пожарной безопасности должны быть включены положения о надлежащем содержании и ремонте систем вентиляции, кондиционирования и противодымной защиты, которые закреплены в статье 138 Технического регламента о требованиях пожарной безопасности.

Так, согласно пункту 2 статьи 138 Технического регламента о требованиях пожарной безопасности противопожарные нормально открытые клапаны должны оснащаться автоматически и дистанционно управляемыми приводами. Использование термочувствительных элементов в составе таких приводов следует предусматривать только в качестве дублирующих. Для противопожарных нормально закрытых клапанов и дымовых клапанов применение приводов с термочувствительными элементами не допускается. Плотность примыкания друг к другу конструкций противопожарных и дымовых клапанов различных типов должна обеспечивать минимально необходимое сопротивление дымогазопроницанию.
Поэтому организации по обслуживанию жилищного фонда при проведении работ по содержанию и ремонту систем вентиляции, кондиционирования и противодымной защиты многоквартирного дома обязаны соблюдать вышеуказанные требования пожарной безопасности в соответствии с инструкциями о мерах пожарной безопасности, которые должны быть разработаны в порядке, установленном законодательством Российской Федерации. ${ }^{5}$

При этом порядок работ по обслуживанию систем вентиляции, кондиционирования и противодымной защиты многоквартирного дома со стороны управляющих и эксплуатирующих организаций должен осуществляться в соответствии с методами, установленными нормативными документами по пожарной безопасности.

Проблема заключается в том, что до настоящего времени в нормативно-правовом порядке не закреплены отдельно требования к содержанию инструкций о мерах пожарной безопасности лиц, ответственных за пожарную безопасность многоквартирного дома, а также не приняты нормативные документы по пожарной безопасности, регулирующие методы проведения работ по содержанию и ремонту систем вентиляции, кондиционирования и противодымной защиты многоквартирного дома.

Последствием этого является тот факт, что подавляющее количество многоквартирных домов обслуживаются жилищно-эксплуатирующими организациями с нарушениями требований пожарной безопасности. При этом под нарушениями требований пожарной безопасности автор подразумевает следующее.

Жилищно-эксплуатирующие организации разрабатывают инструкции о мерах пожарной безопасности многоквартирного дома, которые игнорируют последние научные достижения пожарного дела, так как законодательно не закреплены требования к содержанию данных инструкций. В процессе проведения работ по обслуживанию общего имущества многоквартирного дома, в частности, систем вентиляции, кондиционирования и противодымной защиты организации по обслуживанию жилищного фонда инструкциями о мерах пожарной безопасности не руководствуются.

Поэтому системы вентиляции, кондиционирования и противодымной защиты в многоквартирном доме не обеспечивают пожарную безопасность собственников помещений указанного дома.

Таким образом, порядок разработки жилищно-эксплуатирующими организациями инструкций о мерах пожарной безопасности многоквартирного дома и

\footnotetext{
${ }^{5}$ Назаров, С.A. Судебная пожарно-техническая экспертиза в профилактике преступлений, связанных с пожарами и нарушениями противопожарных правил. Диссертация на соискание ученой степени кандидата юридических наук: 12.00.09 / Назаров С.А. Москва, 1997. - С. 34.
} 


\section{Право и политика $3(159) \cdot 2013$}

требования к содержанию указанных инструкций, с точки зрения правил и норм пожарной безопасности, не регламентированы. Методы проведения работ по обслуживанию систем вентиляции, кондиционирования и противодымной защиты многоквартирного дома в установленном порядке не закреплены.

Согласно статье 8 Федерального закона от 30.12.2009г. № 384-Ф3 «Технический регламент о безопасности зданий и сооружений», ${ }^{6}$ (далее по тексту - Технический регламент о безопасности зданий и сооружений), здание или сооружение должно быть спроектировано и построено таким образом, чтобы в процессе эксплуатации здания или сооружения исключалась возможность возникновения пожара, обеспечивалось предотвращение или ограничение опасности задымления здания или сооружения при пожаре и воздействия опасных факторов пожара на людей и имущество, обеспечивались защита людей и имущества от воздействия опасных факторов пожара и (или) ограничение последствий воздействия опасных факторов пожара на здание или сооружение, а также чтобы в случае возникновения пожара соблюдались следующие требования.

В частности, возможность проезда и подъезда пожарной техники, безопасность доступа личного состава подразделений пожарной охраны и подачи средств пожаротушения к очагу пожара, параметры систем пожаротушения, в том числе наружного и внутреннего противопожарного водоснабжения.

Указанное означает, что при проектировании и строительстве здания или сооружения, в том числе многоквартирного дома должны соблюдаться требования пожарной безопасности в отношении придомовой территории.

При этом условие о соблюдении требований пожарной безопасности в процессе содержания придомовых территорий многоквартирного дома в Техническом регламенте о безопасности зданий и сооружений своего нормативного закрепления не нашло.

Однако в соответствии с пунктом 2 статьи 3 Tехнического регламента о безопасности зданий и сооружений нормы данного технического регламента распространяются на все этапы жизненного цикла здания или сооружения.

По смыслу пункта 2 статьи 3 Технического регламента о безопасности зданий и сооружений положения указанного технического регламента распространяются на все процессы, связанные с общим имуществом здания и сооружения, включая проектирование, строительство, монтаж, наладку, эксплуатацию и утилизацию.

Поэтому общее имущество здания или сооружения, в том числе многоквартирного дома должно быть не только

\footnotetext{
${ }^{6}$ Федеральный закон от 30.12.2009г. № 384-Ф3 «Технический регламент о безопасности зданий и сооружений // Собрание законодательства РФ. - 2010. - № 1. - Ст. 5.
}

надлежащим образом спроектировано и построено, но и должно эксплуатироваться и содержаться в соответствии с требованиями пожарной безопасности.

Отсюда следует, что статья 8 Технического регламента о безопасности зданий и сооружений, по мнению автора, требует внесения в нее юридических изменений и дополнений, в части распространения ее положений и на прилегающую территорию многоквартирного дома.

Наряду с надлежащим содержанием придомовой территории и места общего пользования (системы мусороудаления, лифты и др.) многоквартирного дома должны обслуживаться в соответствии с требованиями пожарной безопасности.

В соответствии со статьей 139 Технического регламента о требованиях пожарной безопасности в составе конструкций стволов мусороудаления не допускается применение материалов, способных к взрывоподобному разрушению при пожаре. Загрузочные клапаны стволов мусороудаления должны выполняться из негорючих материалов и обеспечивать минимально необходимые значения сопротивления дымогазопроницанию.

Из приведенной нормы права следует, что жилищноэксплуатирующие организации в процессе содержания и ремонта систем мусороудаления обязаны соблюдать требования пожарной безопасности. В частности, в ходе проведения обслуживания стволов мусороудаления ремонтно-эксплуатирующие организации должны применять безопасные материалы, которые не способны к взрывоподобному разрушению при пожаре. ${ }^{7}$

Между тем, автор отмечает тот факт, что установленные статьей 139 Технического регламента о требованиях пожарной безопасности противопожарные предписания касательно порядка содержания и ремонта систем мусороудаления здания и сооружения, в том числе многоквартирного дома не в полной мере защищают интересы собственников помещений такого дома.

Так, в указанной статье не перечислены требования пожарной безопасности по содержанию и ремонту таких элементов мусоропровода, как: дефлектор, зачистное моюще-дезинфицирующее устройство и мусоросборная камера с оборудованием. Без должного внимания оказались и другие противопожарные вопросы, с которыми сталкиваются сотрудники организаций, занимающихся обслуживанием систем мусороудаления многоквартирного дома в повседневной деятельности.

Следовательно, требования пожарной безопасности относительно условий содержания и ремонта системы мусороудаления многоквартирного дома должны быть изменены и дополнены в установленном порядке.

\footnotetext{
${ }^{7}$ Широков, A.B. Задачи административно-правового регулирования управления многоквартирными домами // Государство и право. 2008. - №3. - C. 99.
} 
Согласно пункту 1 статьи 140 Технического регламента о требованиях пожарной безопасности пассажирские лифты с автоматическими дверями и со скоростью движения 1 и более метра в секунду должны иметь режим работы, обозначающий пожарную опасность, включающийся по сигналу, поступающему от систем автоматической пожарной сигнализации здания, и обеспечивающий независимо от загрузки и направления движения кабины возвращение ее на основную посадочную площадку, открытие и удержание в открытом положении дверей кабины и шахты.

По смыслу приведенной нормы права, специализирующая организация по обслуживанию и ремонту лифта обеспечивает его безопасную эксплуатацию посредством организации надлежащего режима работы, обозначающего пожарную опасность. Данный режим работы пассажирского лифта, включающийся по сигналу, поступающему от систем автоматической пожарной сигнализации здания, в том числе многоквартирного дома при условии должного содержания и ремонта со стороны эксплуатирующей организации должен гарантировать соблюдение интересов собственников помещений такого дома.

В свою очередь, по мнению автора, остаются не разрешенными ряд юридических проблем в сфере противопожарного обслуживания лифтового хозяйства многоквартирного дома. Так, не регламентированы в установленном порядке требования пожарной безопасности к условиям размещения лифтовых шахт в объемах лестничных клеток многоквартирного дома по результатам проведенного ремонта эксплуатирующей организацией. Но, главное, до настоящего времени в законодательстве Российской Федерации отсутствует норма права, обязывающая организации по обслуживанию лифтового хозяйства страховать риск ответственности за причинение вреда жизни, здоровью или имуществу третьих лиц, в случае пожара на лифте, на весь срок его эксплуатации. Данный факт отрицательно сказывается на противопожарной защищенности собственников общего имущества многоквартирного дома.

Таким образом, вопрос об упорядочении требований пожарной безопасности в процессе содержания и ремонта лифтового хозяйства многоквартирного дома не решен и требует своей дальнейшей юридической проработки.

Требования пожарной безопасности касательно условий содержания и ремонта систем отопления, сетей противопожарного водоснабжения, установок пожарной сигнализации, пожаротушения и электрооборудования многоквартирного дома регулируются СП 7.13130.2009. Сводом правил. Отопление, вентиляция и кондиционирование. Противопожарные требования, ${ }^{8}$ утвержденным

${ }^{8}$ СП 7.13130.2009. Свод правил. Отопление, вентиляция и кондиционирование. Противопожарные требования, утвержденный
Приказом МЧС России от 25 марта 2009 г. № 177 (далее по тексту - Свод правил. Отопление, вентиляция и кондиционирование), СП 5.13130.2009. Сводом правил. Системы противопожарной защиты. Установки пожарной сигнализации и пожаротушения автоматические. Нормы и правила проектирования (вместе с Методикой расчета параметров АУП при поверхностном пожаротушении водой и пеной низкой кратности, Методикой расчета параметров установок пожаротушения высокократной пеной, Методикой расчета массы газового огнетушащего вещества для установок газового пожаротушения при тушении объемным способом, Методикой гидравлического расчета установок углекислотного пожаротушения низкого давления, Общими положениями по расчету установок порошкового пожаротушения модульного типа, Методикой расчета автоматических установок аэрозольного пожаротушения, Методикой расчета избыточного давления при подаче огнетушащего аэрозоля в помещение), ${ }^{9}$ утвержденным Приказом МЧС РФ от 25.03.2009 № 175 (далее по тексту - Свод правил. Системы противопожарной защиты. Установки пожарной сигнализации и пожаротушения автоматические) и СП 6.13130.2009. Сводом правил. Системы противопожарной защиты. Электрооборудование. Требования пожарной безопасности, ${ }^{10}$ утвержденным Приказом МЧС РФ от 25.03.2009 № 176 (далее по тексту - Свод правил. Системы противопожарной защиты. Электрооборудование).

В частности, пунктом 5.1. Свода правил. Отопление, вентиляция и кондиционирование предусмотрено, что температуру теплоносителя для систем отопления и теплоснабжения воздухонагревателей приточных установок, кондиционеров, воздушно-тепловых завес и др. (далее - системы внутреннего теплоснабжения) по условиям

Приказом МЧС России от 25 марта 2009 г. № 177 // Пожарная безопасность. -2010 . - № 1 .

${ }^{9}$ СП 5.13130.2009. Свод правил. Системы противопожарной защиты. Установки пожарной сигнализации и пожаротушения автоматические. Нормы и правила проектирования (вместе с Методикой расчета параметров АУП при поверхностном пожаротушении водой и пеной низкой кратности, Методикой расчета параметров установок пожаротушения высокократной пеной, Методикой расчета массы газового огнетушащего вещества для установок газового пожаротушения при тушении объемным способом, Методикой гидравлического расчета установок углекислотного пожаротушения низкого давления, Общими положениями по расчету установок порошкового пожаротушения модульного типа, Методикой расчета автоматических установок аэрозольного пожаротушения, Методикой расчета избыточного давления при подаче огнетушащего аэрозоля в помещение), утвержденный Приказом МЧС РФ от 25.03.2009 № 175 // Пожарная безопасность. - 2010. - № 3 .

${ }^{10}$ СП 6.13130.2009. Свод правил. Системы противопожарной защиты. Электрооборудование. Требования пожарной безопасности, утвержденный Приказом МЧС РФ от 25.03.2009 № 176 // Пожарная безопасность. - 2010. - № 1 . 


\section{Право и политика 3 (159) 2013}

обеспечения пожарной безопасности зданий, в том числе многоквартирного дома следует принимать не менее чем на $20^{\circ} \mathrm{C}$ ниже температуры самовоспламенения веществ, находящихся в помещении.

В пункте 5.18. Свода правил. Отопление, вентиляция и кондиционирование сказано, что в лестничных клетках, в том числе незадымляемых, не допускается установка отопительных приборов, выступающих от плоскости стен на высоте менее 2,2 м от поверхности проступей и площадок лестницы.

Пункт 9.3.3. Свода правил. Системы противопожарной защиты. Установки пожарной сигнализации и пожаротушения автоматические гласит, что в помещениях, где предусмотрено тушение всего защищаемого объема, должны быть приняты меры по ликвидации необоснованных проемов, против самооткрывания дверей.

В то же время пункт 9.3.4. Свода правил. Системы противопожарной защиты. Установки пожарной сигнализации и пожаротушения автоматические говорит о том, что после окончания работы установки для удаления продуктов горения и порошка, витающего в воздухе, необходимо использовать общеобменную вентиляцию. Допускается для этой цели применять передвижные вентиляционные установки. Осевший порошок удаляется пылесосом или влажной уборкой.

В соответствии с пунктом 4.13. Свода правил. Системы противопожарной защиты. Электрооборудование не допускается совместная прокладка кабельных линий систем противопожарной защиты с другими кабелями и проводами в одном коробе, трубе, жгуте, замкнутом канале строительной конструкции или на одном лотке.

Пункт 4.11. Свода правил. Системы противопожарной защиты. Электрооборудование говорит о том, что не допускается устройство тепловой и максимальной защиты в цепях управления автоматическими установками пожаротушения, отключение которых может привести к отказу подачи огнетушащего вещества к очагу пожара.

Однако, несмотря на детальную выработанность вышеперечисленных положений Свода правил. Отопление, вентиляция и кондиционирование, Свода правил. Системы противопожарной защиты. Установки пожарной сигнализации и пожаротушения автоматические и Свода правил. Системы противопожарной защиты. Электрооборудование, с точки зрения их технико-экономического обоснования, по мнению автора, у данных нормативных правовых актов существует одна общая правовая проблема, которая заключается в следующем.

Указанные нормативные документы носят добровольный характер и не могут быть положены в основу нарушений требований пожарной безопасности по содержанию и ремонту систем отопления, сетей противопожарного водоснабжения, установок пожарной сигнализации, пожаротушения и электрооборудования многоквартирного дома. Данное подтверждается пунктом 1.1. Свода правил. Отопление, вентиляция и кондиционирование, пунктом 1.1. Свода правил. Системы противопожарной защиты. Установки пожарной сигнализации и пожаротушения автоматические и пунктом 1.1. Свода правил. Системы противопожарной защиты. Электрооборудование.

Следовательно, порядок содержания и ремонта систем отопления, сетей противопожарного водоснабжения, установок пожарной сигнализации, пожаротушения и электрооборудования многоквартирного дома, с точки зрения соблюдения противопожарных норм и правил, не регламентирован и нуждается в правовом совершенствовании.

По мнению автора, вышеуказанные проблемы в сфере пожарного надзора за содержанием общего имущества в многоквартирном доме могут быть разрешены следующим образом.

Министерством Российской Федерации по делам гражданской обороны, чрезвычайным ситуациям и ликвидации последствий стихийных бедствий должны быть разработаны и приняты в установленном порядке подзаконные нормативные акты, которые устанавливают порядок издания и утверждения жилищно-эксплуатирующими организациями инструкций о мерах пожарной безопасности многоквартирного дома и требования к их содержанию.

Свод правил. Отопление, вентиляция и кондиционирование. СП 7.13130.2009. необходимо дополнить пунктом, который предусматривает условие о методах проведения работ по обслуживанию систем вентиляции, кондиционирования и противодымной защиты многоквартирного дома.

В статью 8 Технического регламента о безопасности зданий и сооружений необходимо внести изменения и дополнения. Данная статья должна быть сформулирована следующим образом: «здание или сооружение, а также прилегающая территория к ним должны быть спроектированы и построены таким образом, чтобы в процессе эксплуатации здания или сооружения, прилегающей территории к ним исключалась возможность возникновения пожара...».

В статью 139 Технического регламента о требованиях пожарной безопасности необходимо добавить пункты, которые устанавливают требования пожарной безопасности по содержанию и ремонту таких элементов мусоропровода многоквартирного дома, как: дефлектор, зачистное моюще-дезинфицирующее устройство и мусоросборная камера с оборудованием.

Министерством Российской Федерации по делам гражданской обороны, чрезвычайным ситуациям и ликвидации последствий стихийных бедствий должен быть разработан и принят в установленном порядке подзаконный нормативный акт, который устанавливает требования пожарной безопасности к условиям размещения лифтовых шахт в объемах лестничных клеток многоквартирного дома. 
Статью 140 Технического регламента о требованиях пожарной безопасности необходимо дополнить положением, согласно которому организации по обслуживанию лифтового хозяйства обязаны страховать риск ответственности за причинение вреда жизни, здоровью или имуществу третьих лиц, в случае пожара на лифте, на весь срок его эксплуатации.

СП 7.13130.2009. Свод правил. Отопление, вентиляция и кондиционирование, СП 7.13130.2009. Свод правил. Отопление, вентиляция и кондиционирование и СП 6.13130.2009. Свод правил. Системы противопожарной защиты. Электрооборудование должны распространять свое действие и быть обязательными для исполнения жилищно-эксплуатирующими организациями, а не являться нормативными документами по пожарной безопасности в области стандартизации добровольного применения.

\section{Библиография:}

1. Аксенов, С.Г. Особенности противопожарного страхования в законодательстве Российской Федерации // Государство, право, общество (вопросы теории, истории и практики): сборник научных статей. - Уфа: «УЮИ МВД РФ», 2009. - С. 102-104.

2. Гордеев, Д.П. Подходы к регулированию содержания общего имущества в многоквартирном доме // Жилищное право. - 2006. - № 6. - С. 11-28.

3. Греков, А.С. Муниципальная пожарная охрана, обучение мерам пожарной безопасности и противопожарная пропаганда как необходимые элементы обеспечения пожарной безопасности муниципального образования // Бизнес в законе. - 2009. - № 2. - С. 21-24.

4. Греков, А.С. Первичные меры пожарной безопасности: новшества, вводимые техническим регламентом, для органов местного самоуправления // Бизнес в законе. - 2009. - № 1. - С. 40-43.

5. Греков, А.С. Правовое регулирование обеспечения пожарной безопасности и организации деятельности пожарной охраны в России: от истоков становления до 30-х гг. ХХ в. // Правовая политика государства: теория, история, практика. Сборник научных статей. - Пенза: «Информационно-издательский центр ПензГУ», 2009. - Выпуск 5. - С. 102-108.

6. Ершов, А.В., Кондратьев, С.А. Правовая характеристика правонарушений, связанных с качеством работ и услуг в сфере противопожарной защиты // Черные дыры в Российском Законодательстве. - 2009. - № 4. - С. 65-68.

7. Колесников, П. Противопожарное страхование // Закон. - 1998. - № 10. -С.103-105.

8. Макарова, Е.Г. Административно-юрисдикционная деятельность Государственной противопожарной службы МВД России. Диссертация на соискание ученой степени кандидата юридических наук: 12.00.02 / Макарова Е.Г. - Омск, 2000. - 170 с.

9. Назаров, С.А. Судебная пожарно-техническая экспертиза в профилактике преступлений, связанных с пожарами и нарушениями противопожарных правил. Диссертация на соискание ученой степени кандидата юридических наук: 12.00.09 / Назаров С.А. - Москва, 1997. - $174 \mathrm{c}$

10. Попова, Е.С. История развития института крайней необходимости в контексте пожарной безопасности // История государства и права. - 2007. - № 11. - С. 16-17.

11. Плеханова, Т.С. Административные правонарушения в жилищно-коммунальной сфере. Диссертация на соискание ученой степени кандидата юридических наук: 12.00.14 / Плеханова Т.С. - Москва, 2009. - 262 с.

12. Татарян, В.Г. Исторические предпосылки возникновения и развития в Европе и России противопожарного законодательства // История государства и права. 2004. - № 6. - С. 39-41.

13. Татарян, В.Г. Административная ответственность за нарушение требований пожарной безопасности по новому КоАП Российской Федерации // Безопасность бизнеса. - 2003. - № 2. - С. 42-48.

14. Черепов, В. Требования пожарной безопасности к зданиям и сооружениям // Закон. - 1998. - № 10. - С. 91-96.

15. Широков, А.В. Задачи административно-правового регулирования управления многоквартирными домами // Государство и право. - 2008. - №3. - С. 98-103.

\section{References (transliteration):}

1. Aksenov, S.G. Osobennosti protivopozharnogo strakhovaniya v zakonodatel'stve Rossiyskoy Federatsii // Gosudarstvo, pravo, obshchestvo (voprosy teorii, istorii i praktiki): sbornik nauchnykh statey. - Ufa: «UYuI MVD RF», 2009. - S. 102-104.

2. Gordeev, D.P. Podkhody k regulirovaniyu soderzhaniya obshchego imushchestva v mnogokvartirnom dome // Zhilishchnoe pravo. - 2006. - № 6. - S.11-28.

3. Grekov, A.S. Munitsipal'naya pozharnaya okhrana, obuchenie meram pozharnoy bezopasnosti i protivopozharnaya propaganda kak neobkhodimye elementy obespecheniya pozharnoy bezopasnosti munitsipal'nogo obrazovaniya // Biznes v zakone. - 2009. - № 2. - S. 21-24.

4. Grekov, A.S. Pervichnye mery pozharnoy bezopasnosti: novshestva, vvodimye tekhnicheskim reglamentom, dlya organov mestnogo samoupravleniya // Biznes v zakone. - 2009. - № 1. - S. 40-43.

5. Grekov, A.S. Pravovoe regulirovanie obespecheniya pozharnoy bezopasnosti i organizatsii deyatel'nosti pozharnoy okhrany v Rossii: ot istokov stanovleniya 


\section{Право и политика 3 (159) • 2013}

do 30-kh gg. XX v. // Pravovaya politika gosudarstva: teoriya, istoriya, praktika. Sbornik nauchnykh statey. - Penza: «Informatsionno-izdatel'skiy tsentr PenzGU», 2009. - Vypusk 5. - S. 102-108.

6. Ershov, A.V., Kondrat'ev, S.A. Pravovaya kharakteristika pravonarusheniy, svyazannykh s kachestvom rabot i uslug v sfere protivopozharnoy zashchity // Chernye dyry v Rossiyskom Zakonodatel'stve. - 2009. - № 4. - S. 65-68.

7. Kolesnikov, P. Protivopozharnoe strakhovanie // Zakon. - 1998. - № 10. -S.103-105.

8. Makarova, E.G. Administrativno-yurisdiktsionnaya deyatel'nost' Gosudarstvennoy protivopozharnoy sluzhby MVD Rossii. Dissertatsiya na soiskanie uchenoy stepeni kandidata yuridicheskikh nauk: 12.00.02 / Makarova E.G. - Omsk, 2000. - 170c.

9. Nazarov, S.A. Sudebnaya pozharno-tekhnicheskaya ekspertiza v profilaktike prestupleniy, svyazannykh s pozharami i narusheniyami protivopozharnykh pravil. Dissertatsiya na soiskanie uchenoy stepeni kandidata yuridicheskikh nauk: 12.00.09 / Nazarov S.A. - Moskva, 1997. - 174 c.
10. Popova, E.S. Istoriya razvitiya instituta krayney neobkhodimosti v kontekste pozharnoy bezopasnosti // Istoriya gosudarstva i prava. - 2007. - № 11. - S. 16-17.

11. Plekhanova, T.S. Administrativnye pravonarusheniya $\mathrm{v}$ zhilishchno-kommunal'noy sfere. Dissertatsiya na soiskanie uchenoy stepeni kandidata yuridicheskikh nauk: 12.00.14 / Plekhanova T.S. - Moskva, 2009. - 262 s.

12. Tataryan, V.G. Istoricheskie predposylki vozniknoveniya i razvitiya $\mathrm{v}$ Evrope i Rossii protivopozharnogo zakonodatel'stva // Istoriya gosudarstva i prava. - 2004. - № 6. - S. 39-41.

13. Tataryan, V.G. Administrativnaya otvetstvennost' za narushenie trebovaniy pozharnoy bezopasnosti po novomu KoAP Rossiyskoy Federatsii // Bezopasnost' biznesa. 2003. - № 2. - S. 42-48.

14. Cherepov, V. Trebovaniya pozharnoy bezopasnosti $\mathrm{k}$ zdaniyam i sooruzheniyam // Zakon. - 1998. - № 10. S. 91-96.

15. Shirokov, A.V. Zadachi administrativno-pravovogo regulirovaniya upravleniya mnogokvartirnymi domami // Gosudarstvo i pravo. - 2008. - №3. - S. 98-103. 